\section{FDG-PET findings in three cases of Mills' syndrome}

Primary lateral sclerosis (PLS) is a rare subtype of motor neuron disease that exclusively affects upper motor neurons, usually beginning in the lower limbs and, less frequently in the bulbar region or the upper limbs. ${ }^{1}$ In contrast to amyotrophic lateral sclerosis (ALS), PLS typically has a symmetrical presentation and this characteristic was part of the initially proposed PLS criteria. ${ }^{2}$ We report 18 -fluorodeoxyglucose-positron-emission tomography (FDG-PET) findings in three cases with an asymmetrical subtype of PLS, more commonly known as Mills' syndrome. ${ }^{3}$ There is no universally accepted definition of Mills' syndrome, but it is mostly referred to as a slowly progressive motor syndrome with unilateral or asymmetrical pyramidal signs. $^{4}$ In this syndrome, the disease process remains more or less restricted to the motor areas contralateral to the affected side, as suggested by a study visualising microglial activation using 11C-(R)-PK11195 PET. ${ }^{5}$

Three female patients presented with an asymmetrical form of pure upper motor neuron dysfunction, starting in the right arm (patient 1 and 2) and the right leg (patient 3). The asymmetrical presentation correlated with clear regions of hypometabolism on FDG-PET in the contralateral Rolandic and peri-Rolandic areas, as can be seen in ALS or PLS ${ }^{6-8}$ (figure 1). MRI of the brain was unrevealing in all three patients. Extensive investigations did not reveal other underlying pathologies. Mutations in C9orf72, SOD1, FUS and TARDBP were excluded in all three patients. There was a concordance in limb dominance and site of onset, as all three patients were right handed. ${ }^{9}$

No clinical or electrodiagnostic signs of lower motor neuron involvement were noted up to 8 (patient 1 ), 4 (patient 2) and 2 years (patient 3 ) after disease onset. Over this period of time, the disease spread from the right arm to the right leg and, to a lesser degree, to the contralateral side (patient 1), remained restricted to the right arm (patient 2) and spread from the right leg to the right arm (patient 3 ). This suggests a disease propagation by contiguous spread, as opposed to a network-spreading pattern through the corpus callosum in typical PLS.

\section{Koen Van Laere, ${ }^{1}$ Guido Wilms, ${ }^{2}$ Philip Van Damme ${ }^{3,4,5}$}

${ }^{1}$ Department of Nuclear Medicine, University Hospitals Leuven, Leuven, Belgium ${ }^{2}$ Department of Radiology, University Hospitals Leuven, Leuven, Belgium

${ }^{3}$ Department of Neurology, University Hospitals Leuven, Leuven, Belgium ${ }^{4}$ Department of Neurosciences, KU Leuven-University of Leuven, Experimental Neurology and Leuven Research Institute for Neuroscience and Disease (LIND), Leuven, Belgium

${ }^{5}$ Laboratory of Neurobiology, VIB, Vesalius Research Center, Leuven, Belgium

Correspondence to Professor Philip Van Damme, Neurology Department, University Hospitals Leuven, Herestraat 49, Leuven 3000, Belgium; philip.vandamme@uzleuven.be

Acknowledgements The authors acknowledge the skilled help of the radiopharmacy team at UZ Leuven.

Funding This work was supported by a grant from the KU Leuven (GOA/11/014), by the Interuniversity Attraction Poles (IUAP) programme P7/16 of the Belgian

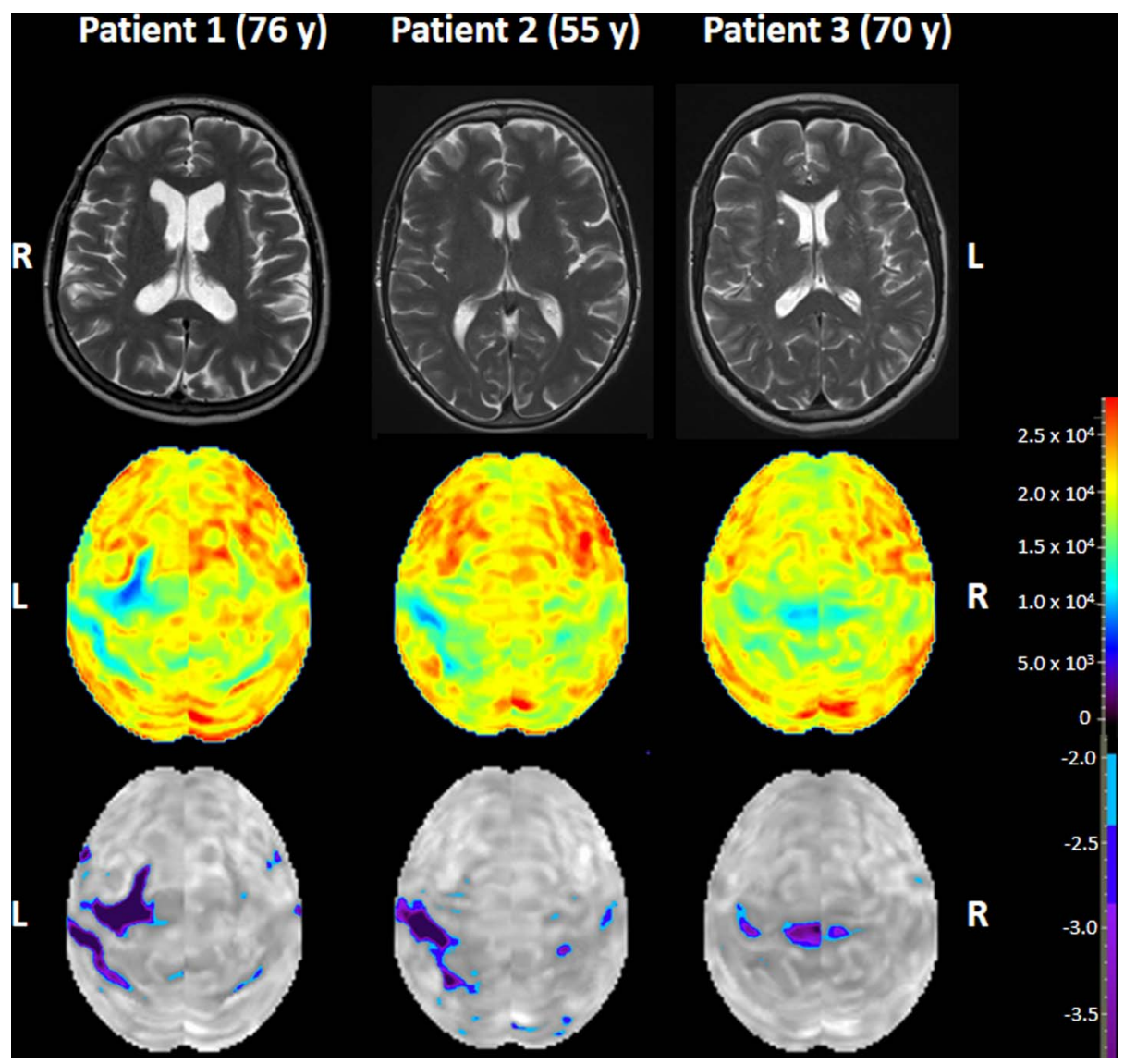

Figure 1 T2-weighted MRI (upper row) and stereotactic surface projections of the brain 18-fluorodeoxyglucose-positron-emission tomography (FDG-PET; middle row, cranial view) with corresponding Z-score images (comparing patient to healthy volunteers; lower row). No lesions on MRI that could explain the hypometabolism on FDG-PET were noted. 
Federal Science Policy Office, by the FWO-Vlaanderen under the frame of E-RARE-2, the ERA-Net for Research on Rare Diseases (PYRAMID) and by a EU Joint Programme- Neurodegenerative Disease Research (JPND) project (STRENGTH). PVD is supported by the Belgian ALS League. KVL and PVD are senior clinical investigators of the Flemish Fund for Scientific Research (FWO, Fonds voor Wetenschappelijk Onderzoek Vlaanderen, Belgium).

\section{Competing interests None.}

Ethics approval Ethics approval was from our institutional IRB (UZ Leuven).

Provenance and peer review Not commissioned; externally peer reviewed.

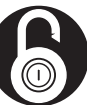

\section{OPEN ACCESS}

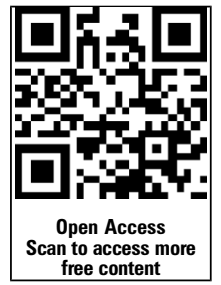

Open Access This is an Open Access article distributed in accordance with the Creative Commons Attribution Non Commercial (CC BY-NC 4.0) license, which permits others to distribute, remix, adapt, build upon this work non-commercially, and license their derivative works on different terms, provided the original work is properly cited and the use is non-commercial. See: http://creativecommons.org/ licenses/by-nc/4.0/
To cite Van Laere K, Wilms G, Van Damme P. J Neurol Neurosurg Psychiatry 2016;87:222-223.

Received 18 November 2014

Revised 29 December 2014

Accepted 7 January 2015

Published Online First 28 April 2015

J Neurol Neurosurg Psychiatry 2016;87:222-223. doi:10.1136/jnnp-2014-309952

\section{REFERENCES}

1 Singer MA, Statland JM, Wolfe Gl, et al. Primary lateral sclerosis. Muscle Nerve 2007;35:291-302.

2 Pringle CE, Hudson AJ, Munoz DG, et al. Primary lateral sclerosis. Clinical features, neuropathology and diagnostic criteria. Brain 1992;115(Pt 2):495-520.

3 Gastaut JL, Bartolomei F. Mills' syndrome: ascending (or descending) progressive hemiplegia: a hemiplegic form of primary lateral sclerosis? I Neurol Neurosurg Psychiatry 1994;57:1280-1.

4 Fernandes PM, Turner MR, Zeidler M, et al. Progressive hemiparesis in a 75-year-old man. Pract Neurol 2014.

5 Turner MR, Gerhard A, Al-Chalabi A, et al. Mills' and other isolated upper motor neurone syndromes: in vivo study with 11C-(R)-PK11195 PET. J Neurol Neurosurg Psychiatry 2005;76:871-4.

6 Van Laere K, Vanhee A, Verschueren J, et al. Value of 18 fluorodeoxyglucose-positron-emission tomography in amyotrophic lateral sclerosis: a prospective study. JAMA Neurol 2014;71:553-61.

7 Pagani M, Chio A, Valentini MC, et al. Functional pattern of brain FDG-PET in amyotrophic lateral sclerosis. Neurology 2014;83:1067-74.

8 Claassen DO, Josephs KA, Peller PJ. The stripe of primary lateral sclerosis: focal primary motor cortex hypometabolism seen on fluorodeoxyglucose F18 positron emission tomography. Arch Neurol 2010;67:122-5.

9 Turner MR, Wicks P, Brownstein CA, et al. Concordance between site of onset and limb dominance in amyotrophic lateral sclerosis. J Neurol Neurosurg Psychiatry 2011;82:853-4. 